\title{
GENETIC AND CLINICAL ANALYSIS OF NONSYNDROMIC HEARING IMPAIRMENT IN PEDIATRIC AND ADULT CASES
}

\author{
Xing J, Liu X*, Tian Y, Tan J, Zhao H
}

\begin{abstract}
*Corresponding Author: Mr. Xinguo Liu, Ear, Nose and Throat Department, The Central Hospital of Zhumadian, No. 747, Zhonghua Road, Zhumadian City, Henan Province, People's Republic of China, 463000. Tel: +86-396-292-6205. Fax:+86-396-272-6530. E-mail: xingglsci@163.com
\end{abstract}

\begin{abstract}
Previous studies have linked GJB2 gene and mitochondrial DNA (mtDNA) mutations to nonsyndromic hearing impairment (NSHI), but no study in China has yet investigated these mutations across all age groups. To fill the gap, this study ascertained 263 patients with NSHI between ages 2 months and 60 years and analyzed the presence of GJB2 gene and mtDNA A1555G/C1494T mutations by polymerase chain reaction (PCR) and DNA sequencing. A total of 20 types of mutations were detected for the GJB2 gene. The GJB2 gene and mtDNA A $1555 \mathrm{G} / \mathrm{C} 1494 \mathrm{~T}$ mutations were detected in 18.63 and $11.41 \%$ cases, respectively. At the first hospital visit, GJB2 gene mutations were detected in 5.97\% of adult patients ( $>18$ years) and $22.96 \%$ pediatric patients $\left(\leq 18\right.$ years) $\left(\chi^{2}=9.506, p=0.002\right)$, and mtDNA A1555G/C1494T mutations were detected in $31.34 \%$ of adult patients and $4.59 \%$ of pediatric patients $\left(\chi^{2}=35.359, p<0.001\right)$. When patients were classified by age at onset of deafness, significantly more $(20.68 \%)$ pediatric patients had GJB2 gene mutations than did adult patients $(0.0 \%)\left(\chi^{2}=4.685\right.$; $p=0.006$ ). Mitochondrial DNA A $1555 \mathrm{G} / \mathrm{C} 1494 \mathrm{~T}$ mutations were detected in $15.38 \%$ of adult-onset and $8.86 \%$ pediatric-onset patients, respectively. Interestingly, most GJB2 gene mutation carriers experienced
\end{abstract}

\footnotetext{
"Ear, Nose and Throat Department, The Central Hospital of Zhumadian, Zhumadian City, Henan Province, People's Republic of China
}

NSHI onset within the first year of life $(65.31 \%)$, while mtDNA A1555G/C1494T mutation carriers experienced onset at any age. Therefore, GJB2 gene mutations appear to contribute to congenital deafness, while mtDNAA1555G/C1494T mutations contribute mainly to acquired deafness in Chinese individuals. Both newborn hearing screening and genetic testing are important to diagnose and treat deafness.

Keywords: Genetic testing; GJB2 gene; mtDNA A1555G/C1494T; Nonsyndromic hearing impairment (NSHI).

\section{INTRODUCTION}

Hearing impairment, or deafness, results from varying degrees of auditory dysfunction that is caused by lesions in the auditory nerve and other nerve centers that perceive and transmit sounds to the brain. Approximately $60.0 \%$ of hearing impairment is associated with genetic factors, and these cases are categorized as either syndromic hearing loss (SHL) or nonsyndromic hearing impairment (NSHI) [1-3]. Nonsyndromic hearing impairment can present at any age and can result from various inheritance patterns, including autosomal recessive, autosomal dominant, $\mathrm{X}$-linked and mitochondrial transmission of genetic alterations. For example, autosomal recessive mutations in the GJB2 gene have been linked with NSHI in Caucasians [4-6], and alterations in the mitochondrial genome [mitochondrial DNA (mtDNA) A1555G/ C1494T] mutations have been associated with NSHI in East Asian individuals [7]. 
Interestingly, studies in Chinese individuals have linked NSHI with both the GJB2 gene and the mtDNA A1555G and C1494T mutations [8-10]. However, the mutation rates for these known alterations differ in NSHI patients across various regions. Additionally, the previous studies focused primarily on pediatric NSHI patients ages 6 to 18 years, thereby excluding other age groups and without any investigation of age-related differences in mutation type and onset of NSHI [8-10]. To fill these gaps, the current study assessed both pediatric and adult NSHI patients and explored the correlations between the age of onset and clinical phenotypes and the GJB2 gene and mtDNAA1555G/C1494T mutation status. These findings provide a scientific basis for developing improved guidelines for the genetic diagnosis of deafness.

\section{PATIENTS AND METHODS}

Patients. This prospective study included 263 NSHI patients who first visited the Ear, Nose and Throat (ENT) Department at the Central Hospital of Zhumadian, Zhumadian City, Henan Province, People's Republic of China (PRC) between March 2008 and March 2013. The 168 males (63.9\%) and 95 females $(36.1 \%)$ had a mean age of $13.1 \pm 10.8$ years (range: 2 months to 60 years). The mean age of NSHI onset was 5.72 years. The study excluded SHL patients and patients with complications resulting from causes such as tympanitis, meningocephalitis, late-stage Meniere's disease, trauma, acoustic neuroma and ototoxic drugs. The subjects were divided into age groups according to their ages at the first hospital visit and at onset of NSHI: adult group $(>18$ years old) and pediatric group ( $\leq 18$ years); the pediatric group was subdivided into infants $(<3$ years $)$, preschool (3-6 years) and school-age (7-18 years) groups. The age of onset was defined as the age at which a patient or patient's family discovered the patient's deafness, or the age at which objective audiometry identified the condition. This study was approved by the Hospital Ethics Committee, and written informed consent was obtained from the patients or their families.

Audiometry and Deafness Phenotype. All the patients were assessed by audiometry, including pure tone audiometry (PTA) or auditory brainstem response (ABR) tests and multiple-frequency audi- tory steady-state response (ASSR). The criteria for analysis and classification of deafness were in accordance with published guidelines [11] as follows: 1) hearing loss was classified by frequency measurements as full-frequency hearing loss $(0.25-8.0 \mathrm{kHz})$, high-frequency hearing loss $(2.0-8.0 \mathrm{kHz})$, mid-frequency hearing loss $(0.5-2.0 \mathrm{kHz})$, or low-frequency hearing loss $(0.25-0.5 \mathrm{kHz}) ; 2)$ according to the stages of speech development, deafness was classified into post-linguistic deafness ( $\geq 3$ years) or pre-linguistic deafness ( $<3$ years); and 3 ) the severity of hearing impairment was judged by the better-hearing ear as being mild [20-40 decibels (dB), hearing level (HL)], moderate (41-70 dB HL), severe (71-95 dB HL), or profound ( $>95 \mathrm{~dB} \mathrm{HL})$.

GJB2 Gene Sequencing. Peripheral venous blood (4 mL) was collected from each subject. The Universal DNA Isolation Kit (BioTeke Corporation, Beijing, PRC) was used to isolate genomic DNA according to the manufacturer's instructions. Polymerase chain reaction (PCR) was used to amplify the GJB2 gene for mutation analysis. The PCR primers, synthesized by Sangon Biotech (Shanghai, PRC) were as follows: downstream primer (5'-GGG CAA TGC TTA AAC TGG C-3'); upstream primer (5'TAT GAC ACT CCC CAG CAC AG-3') [12]. The PCR product was recovered for sequence determination. The sequencing results were compared with the published GJB2 gene sequence (GenBank accession number M86849) to determine the presence of deafness-related sequence variants.

\section{Mutation Analysis of the Mitochondrial}

Genome. Primers for PCR amplification covered mtDNA 1988-2007 and mtDNA 618-635, and PCR amplification involved all fragments of the mitochondrial $12 S$ rRNA gene. Twenty-four sets of primers, covering the whole mitochondrial genome with partially overlapping fragments, were used to perform PCR amplification for mtDNA from patients with the A1555G/C1494T mutations [13]. After the PCR-amplified DNA was recovered from gel with the Agarose Gel DNA Purification Kit Ver. 2.0 (Code No. DV805; TaKaRa Biotech Co. Ltd., Dalin, PRC), the BigDye ${ }^{\circledR}$ Terminator Cycle Sequencing Kit (Microread Genetics, Beijing, PRC) was used to perform sequencing on the ABI PRISM ${ }^{\mathrm{TM}} 3700$ DNA automated sequencer (Biocoen Biotechnology, Beijing, PRC). Sequencing results were compared with the Cambridge Reference Sequence (GenBank accession number NC_001807). 
Statistical Analysis. EpiData version 3.1 was used to create a data bank using double data entry, and logic checks were performed. SAS 9.2 (SAS Institute, Cary, NC, USA) was used to analyze data by the $\chi^{2}$ test. A value of $p<0.05$ was considered to indicate a statistically significant difference.

\section{RESULTS}

In the 263 patients with NSHI, a total of 20 types of sequence changes were detected. These included 15 published mutations in GenBank, of which 10 were known pathogenic mutations (G4D, R32C, 35delG, E47X, W77X, 176-191del16, Q80R, 235delC, S139N and 299-300 delAT), five were previously described polymorphisms (T18I, T86R, G160S, Y38C and 50N) and five were novel sequence variations located in a highly conserved region. Table 1 lists the variations and number of affected alleles.

Rates of Pathological Mutations in Individuals with NSHI. Of the 263 NSHI patients, 49 (18.6\%) exhibited a GJB2 gene mutation: 29 cases were homozygous for a mutation, eight had compound heterozygous mutations and 12 had a single heterozygous mutation (Table 2). The types of mutation included 235delC, 176del6bp, 512insAACG, and 299delAT; 235delC was the most common type of $G J B 2$ gene mutation, occurring in a total of 42 cases, 30 of whom were homozygous and the other 12 were heterozygous. Thirty patients (11.4\%) carried mtDNA mutations; 28 cases had the C1494T mutation and two cases had the A1555G mutation.

Mutation Status Differs with Age of Patient at First Hospital Visit. Patients were categorized by age at the ENT Department visit (Figure 1, Table 3), resulting in 67 adults and 196 pediatric cases ( 72 infants, 54 preschool cases, and 70 school-age cases). The GJB2 gene mutations were detected in $5.97 \%$ adults and $22.96 \%$ pediatric cases; this difference was statistically significant $\left(\chi^{2}=9.506, p=0.002\right)$. In contrast, mtDNA A1555G/C1494T mutations were detected in 31.34\% adults and $4.59 \%$ pediatric cases; this difference was also statistically significant $\left(\chi^{2}=35.359, p<0.001\right)$. Within the pediatric group, the distributions of both

Table 1. Sequence changes in GJB2 gene mutations in 263 NSHI patients.

\begin{tabular}{|c|c|c|c|c|c|}
\hline \multirow[t]{2}{*}{ Amino Acid } & \multirow[t]{2}{*}{ Nucleotide } & \multicolumn{2}{|c|}{$\begin{array}{c}\text { Number of } \\
\text { Affected Alleles }\end{array}$} & \multirow[t]{2}{*}{$\begin{array}{c}\text { Number of } \\
\text { Alleles }\end{array}$} & \multirow[t]{2}{*}{ Category } \\
\hline & & Homozygous & Heterozygous & & \\
\hline V27I & $79 \mathrm{G}>\mathrm{A}$ & 27 & 90 & 144 & polymorphism \\
\hline E114G & $341 \mathrm{~A}>\mathrm{G}$ & 11 & 69 & 91 & polymorphism \\
\hline V37I & $109 \mathrm{G}>\mathrm{A}$ & 1 & 11 & 13 & polymorphism \\
\hline $\mathrm{I} 203 \mathrm{~K}$ & $608 \mathrm{~T}>\mathrm{C}$ & 1 & 8 & 10 & polymorphism \\
\hline $\mathrm{T} 123 \mathrm{~N}$ & $368 \mathrm{C}>\mathrm{A}$ & 0 & 3 & 3 & polymorphism \\
\hline G4D & $11 \mathrm{G}>\mathrm{A}$ & 0 & 1 & 1 & missense \\
\hline 11stop & 30-35delG & 1 & 1 & 3 & deletion/frameshift \\
\hline R32C & $94 \mathrm{C}>\mathrm{T}$ & 0 & 1 & 1 & missense \\
\hline E47X & $139 \mathrm{G}>\mathrm{T}$ & 0 & 1 & 1 & missense \\
\hline 59stop & 176-191del16 & 0 & 1 & 1 & deletion/frameshift \\
\hline W77X & $231 \mathrm{G}>\mathrm{A}$ & 0 & 1 & 1 & missense \\
\hline 79stop & $235 \mathrm{delC}$ & 15 & 15 & 45 & deletion/frameshift \\
\hline Q80R & $239 A>G$ & 0 & 1 & 1 & missense \\
\hline 299-300delAT & 299-300delAT & 3 & 4 & 10 & deletion/frameshift \\
\hline S139N & $416 \mathrm{G}>\mathrm{A}$ & 1 & 0 & 2 & missense \\
\hline T18I & $53 \mathrm{C}>\mathrm{T}$ & 0 & 1 & 1 & novel sequence variation \\
\hline D50N & $148 \mathrm{G}>\mathrm{A}$ & 0 & 1 & 1 & novel sequence variation \\
\hline $\mathrm{Y} 38 \mathrm{C}$ & $203 \mathrm{~A}>\mathrm{G}$ & 0 & 1 & 1 & novel sequence variation \\
\hline T86R & $257 \mathrm{C}>\mathrm{G}$ & 0 & 1 & 1 & novel sequence variation \\
\hline G160S & $478 \mathrm{G}>\mathrm{A}$ & 0 & 1 & 1 & novel sequence variation \\
\hline
\end{tabular}




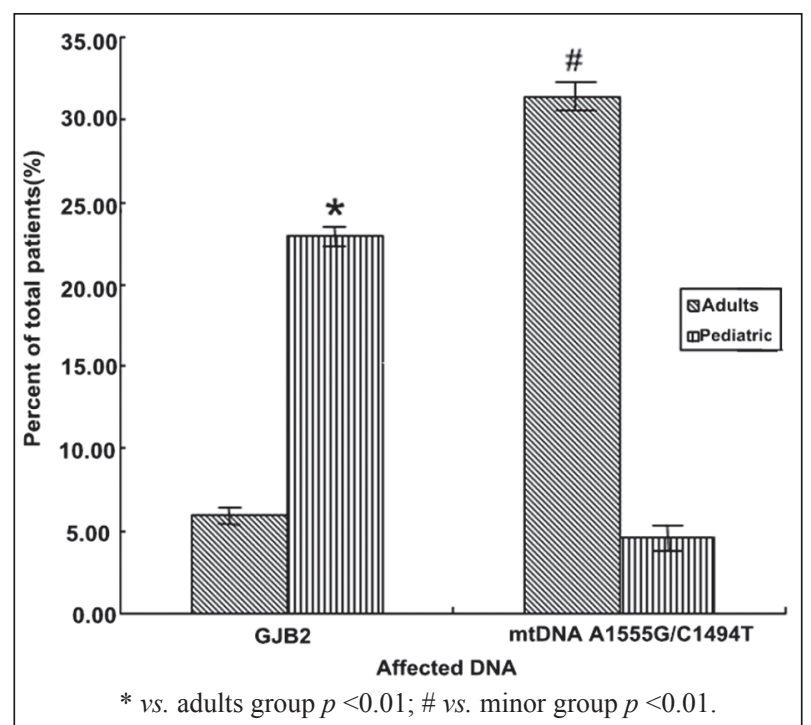

Figure 1. Mutation rates for patients with NSHI classified by age at first hospital visit.

GJB2 gene and mtDNA mutations among the subcategories were statistically similar (each $p$ value $>0.05$ ).

Mutation Status Differs with Age of Onset of Deafness. Patients were divided by age of onset of

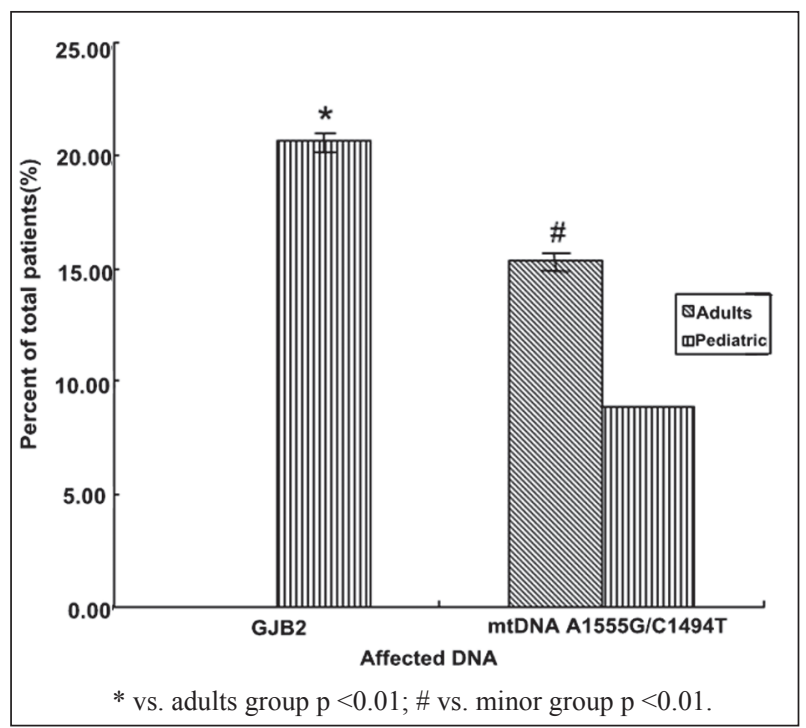

Figure 2. Mutation rates for patients with NSHI classified by age at onset of deafness.

NSHI, resulting in 26 adult cases and 237 pediatric cases (186 infants, 21 preschool cases, and 30 schoolage cases) (Figure 2, Table 4). The GJB2 gene mutations were not detected in any of the adult-onset cases,

Table 2. Frequency of the GJB2 gene variations in patients with NSHI.

\begin{tabular}{|c|c|c|c|}
\hline Amino Acid & Nucleotide & Number of Alleles & Frequency $(\%)$ \\
\hline E47X & $139 \mathrm{G}>\mathrm{T}$ & 1 & 1.52 \\
\hline $\mathrm{R} 32 \mathrm{C}$ & $94 \mathrm{C}>\mathrm{T}$ & 1 & 1.52 \\
\hline G4D & $11 \mathrm{G}>\mathrm{A}$ & 1 & 1.52 \\
\hline W77X & $231 \mathrm{G}>\mathrm{A}$ & 1 & 1.52 \\
\hline 59stop & 176-191del16 & 1 & 1.52 \\
\hline Q80R & $239 \mathrm{~A}>\mathrm{G}$ & 1 & 1.52 \\
\hline S139N & $416 \mathrm{G}>\mathrm{A}$ & 2 & 3.03 \\
\hline 11 stop & 30-35delG & 3 & 4.55 \\
\hline 299-300delAT & 299-300delAT & 10 & 15.15 \\
\hline 79stop & $235 \mathrm{delC}$ & 45 & 68.18 \\
\hline Total & & 66 & 100.00 \\
\hline
\end{tabular}

Table 3. Mutations status in pediatric cases of NSHI categorized by age at the first hospital visit.

\begin{tabular}{|l|c|c|c|c|c|}
\hline Mutation Status & $\begin{array}{c}\text { Infants } \\
(\boldsymbol{n}=\mathbf{7 2})\end{array}$ & $\begin{array}{c}\text { Preschool } \\
(\boldsymbol{n}=\mathbf{5 4})\end{array}$ & $\begin{array}{c}\text { School Age } \\
(\boldsymbol{n}=\mathbf{7 0})\end{array}$ & $\boldsymbol{\chi}^{\mathbf{2} \text { Test }}$ & $\boldsymbol{p}$ Value \\
\hline $\begin{array}{l}\text { GJB2: } \\
\text { - mutation }\end{array}$ & $16(22.22 \%)$ & $14(25.93 \%)$ & $15(21.43 \%)$ & & \\
- no mutation & $56(77.78 \%)$ & $40(74.07 \%)$ & $55(78.57 \%)$ & 0.384 & 0.826 \\
\hline $\begin{array}{l}\text { mtDNA A1555G/C1494T: } \\
\text { - mutation }\end{array}$ & $1(1.39 \%)$ & $2(3.70 \%)$ & $6(8.57 \%)$ & & \\
- no mutation & $71(98.61 \%)$ & $52(96.30 \%)$ & $64(91.43 \%)$ & 4.314 & $0.143^{*}$ \\
\hline
\end{tabular}

\footnotetext{
* Fisher's exact test
} 
Table 4. Mutation status in pediatric cases of NSHI categorized by age at onset of deafness.

\begin{tabular}{|l|c|c|c|c|c|}
\hline Mutation Status & $\begin{array}{c}\text { Infants } \\
(\boldsymbol{n}=\mathbf{1 8 6})\end{array}$ & $\begin{array}{c}\text { Preschool } \\
(\boldsymbol{n}=\mathbf{2 1})\end{array}$ & $\begin{array}{c}\text { School Age } \\
(\boldsymbol{n}=\mathbf{3 0})\end{array}$ & $\chi^{\mathbf{2} \text { Test }}$ & $\boldsymbol{p}$ Value \\
\hline GJB2: & & & & & \\
- mutation & $44(23.66 \%)$ & $2(9.52 \%)$ & $3(10.00 \%)$ & 4.685 & 0.096 \\
- no mutation & $142(76.34 \%)$ & $19(90.48 \%)$ & $27(90.00 \%)$ & & \\
\hline mtDNA A1555G/C1494T: & $18(9.68 \%)$ & $2(9.52 \%)$ & $5(16.67 \%)$ & 1.363 & $0.502 *$ \\
- mutation & $168(90.32 \%)$ & $19(90.47 \%)$ & $25(83.33 \%)$ & \\
- no mutation & & & & \\
\hline
\end{tabular}

* Fisher's exact test

Table 5. Mutation status in pediatric cases of NSHI cases by pre-lingual or post-lingual onset of deafness.

\begin{tabular}{|c|c|c|c|c|}
\hline Mutation Status & $\begin{array}{l}\text { Pre-lingual Deafness } \\
\text { ( } \leq 3 \text { years) }\end{array}$ & $\begin{array}{l}\text { Post-lingual Deafness } \\
\text { ( }>3 \text { and }<18 \text { years) }\end{array}$ & $\chi^{2}$ Test & $p$ Value \\
\hline $\begin{array}{l}\text { GJB2: } \\
\text { - mutation } \\
\text { - no mutation }\end{array}$ & $\begin{array}{r}44(23.66 \%) \\
142(76.34 \%)\end{array}$ & $\begin{array}{c}5(9.80 \%) \\
46(90.20 \%)\end{array}$ & 4.683 & 0.031 \\
\hline $\begin{array}{l}\text { mtDNA A1555G/C1494T: } \\
\text { - mutation } \\
\text { - no mutation }\end{array}$ & $\begin{array}{c}18(9.68 \%) \\
168(90.32 \%)\end{array}$ & $\begin{array}{r}7(13.73 \%) \\
44(86.27 \%)\end{array}$ & 0.695 & 0.404 \\
\hline
\end{tabular}

Table 6. Distribution of age of onset in patients with the GJB2 gene and mtDNA mutations.

\begin{tabular}{|l|c|c|c|c|c|c|}
\hline Mutation Status & Total & \multicolumn{3}{|c|}{ Age at Onset } & $\chi^{2}$ Test & $p$ Value \\
\hline & & $\leq 1$ year & $>1$ and $\leq 3$ years & $>3$ years & & \\
\hline GJB2 gene & 49 & $32(65.31 \%)$ & $11(22.45 \%)$ & $6(12.24 \%)$ & 13.383 & 0.001 \\
\hline mtDNA mutations & 30 & $8(26.67 \%)$ & $9(30.00 \%)$ & $13(43.33 \%)$ & & \\
\hline
\end{tabular}

but were present in $20.68 \%$ of pediatric cases; this difference was statistically significant $(p=0.006)$. In contrast, mtDNA A1555G/C1494T mutations were detected in $15.38 \%$ of adult-onset patients and $8.86 \%$ of pediatric cases; this difference was not statis-tically significant $(p=0.288)$. Differences in mutation distributions in the pediatric subcategories were not statistically significant for either the GJB2 gene or mtDNA $\mathrm{A} 1555 \mathrm{G} / \mathrm{C} 1494 \mathrm{~T}$ mutations (each $p$ value $>0.05$ ).

For the pediatric cases, hearing loss was further classified as either pre-lingual or post-lingual (Table 5). The difference in GJB2 gene mutation between these two groups was statistically significant $\left(\chi^{2}=\right.$ 4.683, $p=0.031)$; in contrast, the difference in mtDNA A1555G/C1494T mutations between these groups was not statistically significant $\left(\chi^{2}=0.695, p=0.404\right)$.

Age Distributions Differ Between NSHI Patients with $G J B 2$ Gene Mutations and Those with mtDNA Mutations. Patients who were positive for any mutation were subdivided into three age categories by mutation status and age of onset (Table 6). Patients with the GJB2 gene mutation primarily experienced onset within the first year of life (65.31\%). Those with mtDNA A1555G/ C1494T mutations were nearly evenly divided between the three onset age groups. However, the difference in onset age distributions between those with GJB2 gene mutations and those with mtDNA mutations was statistically significant $(p<0.05)$.

Hearing Loss Phenotypes Differ by Mutation Status. Finally, patients were categorized according to their hearing loss phenotypes and mutation status. Patients with mtDNA A1555G/C1494T mutations generally exhibited mild-to-moderate hearing loss. In contrast, most patients with $G J B 2$ gene mutations exhibited profound hearing loss. This difference in phenotypic distributions was statistically significant $(p<0.05)$ (Table 7). Of the 30 patients with mtDNA A1555G/C1494T mutations, 22 underwent complete PTA. Severity of hearing loss was again judged according to the multiple grading standards: published recommendations [11], ISO-1964 criteria, and ISO1997 criteria, as well as the mean hearing thresholds 
Table 7. Comparison of the degree of hearing loss between patients with the GJB2 gene and mtDNA mutations.

\begin{tabular}{|c|c|c|c|c|c|c|c|}
\hline Mutation Status & Total & & Degree of & ring Loss & & $\chi^{2}$ Test & $p$ Value \\
\hline & & Mild & Moderate & Severe & Profound & & \\
\hline GJB2 gene & 49 & $3(6.12 \%)$ & $5(10.20 \%)$ & $9(18.37 \%)$ & $32(65.31 \%)$ & & $<0.001 *$ \\
\hline mtDNA mutations & 30 & $1(3.33 \%)$ & $15(50.00 \%)$ & $0(0.00 \%)$ & $14(46.67 \%)$ & & \\
\hline
\end{tabular}

* Fisher's exact test

Table 8. Comparison of the degree of hearing loss by grading standard of 22 patients with mtDNA mutations.

\begin{tabular}{|l|c|c|c|c|c|}
\hline Grading Standard & \multicolumn{5}{|c|}{ Degree of Hearing Loss } \\
\hline & Mild & Moderate & Moderate to Severe & Severe & Profound \\
\hline Guidelines [11] & 1 & 11 & - & 3 & 7 \\
\hline ISO-1964, ${ }^{\mathrm{a}, \mathrm{b}}$ & 5 & 6 & 5 & 1 & 5 \\
\hline ISO-1997 & 1 & 8 & - & 5 & 8 \\
\hline $0.25-8.0 \mathrm{kHz}$ & 0 & 6 & 7 & 2 & 7 \\
\hline $1.0-4.0 \mathrm{kHz}$ & 0 & 4 & 5 & 7 & 15 \\
\hline $4.0-8.0 \mathrm{kHz}$ & 0 & 0 & 0 & & 7 \\
\hline
\end{tabular}

at $0.25-8.0 \mathrm{kHz}$ (full frequency band), $1.0-4.0 \mathrm{kHz}$ and $4.0-8.0 \mathrm{kHz}$ (Table 8 ). The difference between hearing loss judged according to the ISO-1964 criteria and the one judged according to the mean hearing threshold at $4.0-8.0 \mathrm{kHz}$, was statistically significant $(p<0.001)$; however, the differences between hearing loss judged according to the mean hearing threshold at 4.0-8.0 kHz and the one according to the other criteria were not statistically significant (each $p$ value $>0.05$ ).

\section{DISCUSSION}

Genetic diagnosis can help determine the etiology of NSHI for most patients with genetic deafness. The GJB2 gene mutation is the most common cause of genetic deafness of nuclear origin. In this study, the GJB2 gene mutation was detected in $18.63 \%$ of cases, which was lower than the report from Gabriel et al. [14] (22.0\%). The mutations included 235delC, 76dell6bp, 512insAACG, and 299delAT. The $235 \mathrm{delC}$ was most common, and comprised both the homozygous mutation and the compound heterozygous mutation. This finding supports a previous report that a heterozygous mutation of a $G J B 2$ gene could cause deafness [15]. Furthermore, GJB2 gene mutations were more common in pediatric cases, both by age of onset and age of first hospital visit, than in adult cases. Interestingly, a GJB2 gene mutation was most common in cases of pre-lingual deafness, suggesting that a GJB2 gene mutation is a significant contributor to pre-lingual deafness in Chinese individuals. Moreover, the age of deafness onset in patients with GJB2 gene mutations was typically within the first year of life; therefore, clinicians should perform routine tests for GJB2 gene mutations in pediatric NSHI patients. The GJB2 gene encodes the gap junction-connexin 26 (CX26) protein [16]. The 235 delC mutation encodes a defective CX26 that results in an ineffective gap junction disrupting potassium homeostasis in the inner ear, particularly of the Corti's organ, which subsequently leads to sensorineural deafness [17].

The hot-spot of mtDNAA1555G/C1494T mutations is located at the highly conserved coding region of the $12 S r R N A$ gene [18]. In this study, $11.41 \%$ cases had mtDNA A1555G/C1494T mutations, mostly comprising the C1494T mutation. The age of onset of hearing loss did not differ by mtDNAA $1555 \mathrm{G} /$ C1494T mutation status, suggesting that these mutations can result in congenital deafness or acquired progressive deafness. Thus, clinicians should perform genetic screening for newborns with a matrilineal history of deafness.

Interestingly, the findings of this study also indicated that patients with mtDNA A1555G/C1494T mutations more often exhibit mild hearing loss, often with some residual hearing. In contrast, most patients with $G J B 2$ gene mutations exhibited profound hearing loss. However, the findings suggest that progressive aggravation of deafness is caused by mtDNA 
A1555G/C1494T mutations. The 22 patients with mtDNAA1555G/C1494T mutations who underwent complete PTA had more distinguishable hearing loss phenotypes. Previous studies reported differences in the deafness phenotypes of matrilineal family members carrying A1555G/C1494T mutations, in which the age of onset, the severity of hearing loss, and the hearing threshold curves differed despite shared genotypes [19-21]. The grading results suggest that deaf patients can be more easily discovered earlier by judging the severity of hearing loss according to the mean hearing threshold at 4.0-8.0 kHz. Clinically, most matrilineal family members carrying mtDNA A1555G/C1494T mutations have no self-felt hearing loss, but hearing tests can show that the high frequency decreases, and the low frequency and the stages of speech development are mostly normal. Therefore, when judging the severity of hearing loss in patients, clinicians should pay attention to the hearing frequency at $4.0-8.0 \mathrm{kHz}$ and perform genetic susceptibility testing for those with decreased highfrequency hearing.

In summary, a GJB2 gene mutation typically results in congenital deafness, while mtDNAA1555G/ C1494T mutations can result in congenital deafness or acquired and progressive deafness. Thus, newborn hearing screening combined with genetic screening is of great significance for early discovery, and appropriate interventions, for genetic deafness.

Declaration of Interest. The authors report no conflicts of interest. The authors alone are responsible for the content and writing of this article.

\section{REFERENCES}

1. Martini A, Dafydd S, Read AP, Eds. Genes, Hearing, and Deafness: From Molecular Biology to Clinical Practice. Boca Raton, FL, USA: CRC Press, 2013.

2. Shearer AE, Smith RJ. Genetics: Advances in genetic testing for deafness. Curr Opin Pediatr. 2012; 24(6): 679-686.

3. Shearer AE, Hildebrand MS, Sloan CM, Smith RJ. Deafness in the genomics era. Hear Res. 2011; 282(1-2):1-9.

4. Daneshi A, Hassanzadeh S, Emamdjomeh H, Mohammadi SH, Arzhangi S, Farhadi M, et al. Prevalence of GJB2-associated deafness and outcomes of cochlear implantation in Iran. J Laryngol Otol. 2011; 125(05): 455-459.

5. Duman D, Tekin M. Autosomal recessive nonsyndromic deafness genes: A review. Front Biosci (Landmark Ed). 2012; 17: 2213-2236.

6. Ramsebner R, Ludwig M, Lucas T, de Jong D, Hamader G, del Castillo I, et al. Identification of a SNP in a regulatory region of GJB2 associated with idiopathic nonsyndromic autosomal recessive hearing loss in a multicenter study. Otol Neurotol. 2013; 34(4): 650-656.

7. Yao YG, Salas A, Bravi CM, Bandelt HJ. A reappraisal of complete mtDNA variation in East Asian families with hearing impairment. Hum Genet. 2006; 119(5): 505-515.

8. Yuan Y, You Y, Huang D, Cui J, Wang Y, Wang Q, et al. Comprehensive molecular etiology analysis of non-syndromic hearing impairment from typical areas in China. J Transl Med. 2009; 7(79): 1-12.

9. Ou QS, Cheng ZJ, Yang B, Jiang L, Chen J. Analysis of the ratio of mitchondrial DNA with A1555G mutant to wild type in deaf patients of Fujian province in China by a new method and its relationship with the severity of hearing loss. Chin Med J (Engl). 2011; 124(20): 3347-3352.

10. Lu SY, Nishio S, Tsukada K, Oguchi T, Kobayashi K, Abe S, et al. Factors that affect hearing level in individuals with the mitochondrial 1555A.G mutation. Clin Genet 2009; 75(5): 480-484.

11. Stephens D. Definitions, Protocols \& Guidelines in Genetic Hearing Impairment. Audiological Terms. Letchworth, Hertfordshire, UK: Whurr Publishers, 2001.

12. Jin L, Yang A, Zhu Y, Zhao J, Wang X, Yang L, et al. Mitochondrial tRNA Ser (UCN) gene is the hot spot for mutations associated with aminoglycoside-induced and non-syndromic hearing loss. Biochem Biophys Res Comm. 2007; 361(1): 133-139.

13. Chen B, Sun D, Yang L, Zhang C, Yang A, Zhu Y, et al. Mitochondrial ND5 T12338C, tRNA(Cys) T5802C, and tRNA (Thr) G15927A variants may have a modifying role in the phenotypic manifestation of deafness associated $12 \mathrm{~S}$ rRNAA1555G mutation in three Han Chinese pedigrees. Am J Med Genet A. 2008; 146(10): 1248-1258.

14. Gabriel H, Kupsch P, Sudendey J, Winterhager E, Jahnke K, Lautermann J. Mutations in the con- 
nexin26/ GJB2 gene are the most common event in non syndromic hearing loss among the German population [J]. Hum Mutat. 2001; 17(6): 521-522.

15. Gallant E, Francey L, Fetting H, Kaur M, Hakonarson $\mathrm{H}$, Clark D, et al. Novel COCH mutation in a family with autosomal dominant late onset sensorineural hearing impairment and tinnitus. Am J Otolaryngol. 2013; 34(3): 230-235.

16. Todt I, Hennies HC, Basta D, Ernst A. Vestibular dysfunction of patients with mutations of Connexin 26. Neuroreport. 2005; 16(11): 1179-1181.

17. Thatcher A, Le Prell C, Miller J, Green G. ACEMg supplementation ameliorates progressive Connexin 26 hearing loss in a child. Int $\mathrm{J}$ Pediatr Otorhinolaryngol. 2014; 78(3): 563-565.

18. Ma T, Xue X, Dai P, Cao X, Chi J, Deng J, et al. Epidemiological studies on mtDNA 12S rRNA A $1555 \mathrm{G}$ mutation of 10 non syndromic hearing loss families in Yunnan province. Lin Chuang
Er Bi Yan Hou Tou Jing Wai Ke Za Zhi. 2012; 26(13): 581-585.

19. Lu J, Li Z, Zhu Y, Yang A, Li R, Zheng J, et al. Mitochondrial 12S rRNA variants in 1642 Han Chinese pediatric subjects with aminoglycosideinduced and non-syndromic hearing loss. Mitochondrion. 2010; 10(4): 380-390.

20. Wang X, Lu J, Zhu Y, Yang A, Yang L, Li R, et al. Mitochondrial tRNAThr G15927A mutation may modulate the phenotypic manifestation of ototoxic $12 \mathrm{~S}$ rRNA A1555G mutation in four Chinese families. Pharmacogenet Genom. 2008; 18(12): 1059-1070.

21. Lu J, Qian Y, Li Z, Yang A, Zhu Y, Li R, et al. Mitochondrial haplotypes may modulate the phenotypic manifestation of the deafness-associated 12S rRNA $1555 \mathrm{~A}>\mathrm{G}$ mutation. Mitochondrion. 2010; 10(1): 69-81. 